\title{
A radical shift in the diagnostic approach to diffuse gliomas
}

\section{Rajesh Panth ${ }^{1}$}

${ }^{1}$ Upendra Devkota Memorial National Institute of Neurological and Allied Sciences Bansbari, Kathmandu, Nepal

\section{Keywords: \\ Gliomas; \\ IDH; \\ 1p/19q-codeletion;}

\begin{abstract}
Astrocytic tumours comprise the majority of central nervous system tumours and they have been traditionally graded as recommended by World Health Organization on the basis of atypia, mitoses, microvascular proliferation and necrosis. The 2016 WHO classification of diffuse gliomas incorporates both molecular and histological criteria to categorize these tumours to better predict behavior. A layered diagnostic format is now the recommended approach with the WHO grade being assigned on histological criteria to be supplemented by molecular characterization once the result of isocitrate dehydrogenase is available. The presence of $1 \mathrm{p} / 19 \mathrm{q}$-codeletion has now been included in the definition of oligodendrogliomas. Oligoastrocytomas have now almost vanished as an entity because they are classified as either astrocytomas or oligodendrogliomas after molecular testing. Tests have to be modified in resource limited settings to reach a molecular diagnosis based on new scientific literature and research.
\end{abstract}

\section{Correspondence:}

Dr. Rajesh Panth, $M D$

Consultant Pathologist,

Upendra Devkota Memorial National Institute of Neurological and Allied Sciences

Email: rajeshreeta1981@yahoo.com

Reveived : February $16^{\text {th }} 2020$; Accepted : March $18^{\text {nd }} 2020$

Citation: Panth R. A radical shift in the diagnostic approach to diffuse gliomas. JPN 2020;10:166372 DOI 10.3126/jpn.v10i1.28947

Copyright: This is an open-access article distributed under the terms of the Creative Commons Attribution 4.0 International License, which permits unrestricted use, distribution, and reproduction in any medium, provided the original author and source are credited.

\section{INTRODUCTION}

Perineuronal sattelitosis, perivascular accumulation and subpial concentration of tumour cells comprise the secondary structures of Scherer which confirm the histological diagnosis of diffuse gliomas. ${ }^{1}$ Astrocytic tumours comprise the majority of central nervous system (CNS) tumours and they have been traditionally graded as recommended by World Health Organization (WHO) on the basis of atypia, mitoses, microvascular proliferation and necrosis. It has already been four years since 2016 when the WHO proposed a major change in the diagnostic criteria for adult diffuse gliomas by incorporating an integrated histo-molecular approach. ${ }^{2}$ This modification was widely welcomed because of its potentiality to drastically reduce 
Table 1: WHO grading criteria of diffuse astrocytic tumors

\begin{tabular}{lcl}
\hline \multicolumn{1}{c}{ Tumour entity } & WHO Grade & Histological Criteria \\
\hline Diffuse astrocytoma & II & Nuclear atypia \\
\hline $\begin{array}{l}\text { Anaplastic } \\
\text { astrocytoma }\end{array}$ & III & $\begin{array}{l}\text { frequent mitotic } \\
\text { activity }\end{array}$ \\
Glioblastoma & IV & $\begin{array}{l}\text { Microvascular prolifera- } \\
\text { tion and / or necrosis }\end{array}$ \\
\hline
\end{tabular}

inter-observer variation in the diagnosis of diffuse gliomas, thus reducing the danger of detrimental consequences for patients. ${ }^{3}$ This review article discusses the histomolecular approach to the diagnosis of diffuse gliomas as recommended in the WHO 2016 classification and also highlights the approach in resource limited settings.

\section{PREREQUISITES TO THE MORPHOLOGICAL EVALUATION}

A short clinical history of few weeks and months usually imply a rapidly growing high-grade glioma while a long history of seizures point towards a lower grade, slowly growing glioma. Clinical parameters like Karnofsky and neurologic performance scores, neurocognitive assessment and the overall patient functional scores help in assessing response to treatment. ${ }^{4}$

\section{MAGNETIC RESONANCE IMAGES ARE GROSS FEATURES}

It can be disastrous to report on neuropathology specimens without reviewing the magnetic resonance imaging (MRI) comprising of plain T1-weighted, T2-weighted, fluidattenuated inversion recovery (FLAIR) and post-contrast T1-weighted images. ${ }^{5}$ Contrast enhancement should alert the pathologist not to diagnose low-grade diffuse glioma outright and to consider and communicate possible sampling error to the neurosurgeon when histological features are out of tune with the imaging impression. Recent studies are focusing on the identification of MRI features that correlate with IDH mutational status in diffuse gliomas. ${ }^{6}$ It cannot be overemphasized that MRI images and not just the tissue pieces comprise the gross features in neuropathology.

\section{SURGICAL MANAGEMENT OF DIFFUSE GLIOMAS}

Safe maximal resection constitutes the primary aim of surgery in diffuse gliomas to relieve raised intracranial pressure and to obtain tissue for diagnosis and molecular studies. ${ }^{7,8}$ Stereotactic guided biopsy is performed when larger resection is not possible due to a deep seated, diffuse midline or an eloquent area location. ${ }^{9}$ The tiny core of tissue obtained during stereotactic biopsy is usually sufficient to generate an integrated histo-molecular diagnosis to prognosticate the patient.

\section{HISTOLOGICAL DIAGNOSIS AND WHO GRADING OF DIFFUSE GLIOMAS}

Histological evaluation of gliomabegins with the appreciation of increased cellularity in a fibrillary background. In addition to the presence of occasional enlarged and angulated hyperchromatic nuclei elaborating fibres, the presence of microcysts, calcification and / or mitotic figures shifts the balance in favour of glioma in a difficult situation when we are struggling to differentiate glioma from gliosis (Fig. 1). Once the diagnosis of glioma is made, the next task is to confirm the diffuse nature of the neoplasm. The presence of perinuronal satellitosis, perivascular accumulation or subpial concentration of tumour cells in the neighbouring cortex comprises the secondary structures of Scherer which confirm the histological diagnosis of diffuse gliomas. ${ }^{1}$ Perineuronal satellitosis is the most prevalent among these to reach the diagnosis of diffuse glioma (Fig. 2). Careful assessment of the entire tumour tissue for the presence of atypia, frequent mitoses, microvascular proliferation and / or necrosis helps us to grade the diffuse gliomas (Fig. 2, Table 1 and Table 2). The number of mitotic figures to upgrade the tumour from WHO Grade II to III is not fixed, but most practicing neuropathologists use a cut-off of $6 /$ 10 high power fields. 2 The size of the biopsy sample too has to be taken into account; while a single mitotic figure in a small stereotactic biopsy specimen may be sufficient to upgrade, it definitely is not on a larger resection specimen. ${ }^{2}$

\section{WHO 2016 CLASSIFICATION OF DIFFUSE GLIOMAS}

In departure from its previous classifications, WHO in 2016, for the first time, defined diffuse gliomas based on both histological and molecular alterations with the primary intention to provide higher diagnostic accuracy

Table 2: Histological assessment of gliomas

\begin{tabular}{lll}
\hline Assessment & Approach & Application \\
\hline Cellularity & $\begin{array}{l}\text { Distance between two nuclei less than the diameter } \\
\text { of nuclei, touching (kissing) }\end{array}$ & Gliosis vs Glioma \\
Atypia & $\begin{array}{l}\text { Nuclear enlargement, hyperchromatism, irregular } \\
\text { nuclear membrane, pleomorphism }\end{array}$ & Gliosis vs Glioma (Grade) \\
Mitoses & $\begin{array}{l}\text { Difficult to identify (classic chromatin separation } \\
\text { not seen ): Combine with cellularity, pleomor- } \\
\text { phism, atypical mitoses }\end{array}$ & Grade: WHO Grade II vs III \\
Microvascular proliferation & Multilayering, glomeruloid tufts & Grade: WHO Grade III (Oligo), IV (Glioblastoma) \\
Necrosis & Pseudopalisading/Ishaemic & Grade: WHO Grade III (Oligo), IV (Glioblastoma)
\end{tabular}


Table 3: WHO grades of diffuse astrocytic and oligodendorglial tumors ${ }^{2}$

\begin{tabular}{|c|c|c|c|}
\hline ADiffuse gliomas / WHO grades & II & III & IV \\
\hline $\begin{array}{l}\text { Diffuse astrocytoma, IDH-mutant } \\
\text { Gemistocytic astrocytoma, IDH-mutant } \\
\text { Diffuse astrocytoma, IDH-wildtype } \\
\text { Diffue astrocytoma, NOS }\end{array}$ & $\begin{array}{l}* \\
* \\
* \\
*\end{array}$ & & \\
\hline $\begin{array}{l}\text { Anaplastic astrocytoma, IDH-mutant } \\
\text { Anaplastic astrocytoma, IDH-wildtype } \\
\text { Anaplastic astrocytoma, NOS }\end{array}$ & & $\begin{array}{l}* \\
* \\
*\end{array}$ & \\
\hline $\begin{array}{l}\text { Glioblastoma, IDH-wildtype } \\
\text { Giant cell glioblastoma } \\
\text { Gliosarcoma } \\
\text { Epithelioid glioblastoma } \\
\text { Glioblastoma, IDH-mutant } \\
\text { Glioblastoma, NOS }\end{array}$ & & & $\begin{array}{l}* \\
* \\
* \\
* \\
*\end{array}$ \\
\hline Diffuse mildine glioma, H3 K27M-mutant & & & $*$ \\
\hline $\begin{array}{l}\text { Oligodendroglioma, IDH-mutant and } 1 \mathrm{p} / 19 \mathrm{q} \text {-codeleted } \\
\text { Oligodendroglioma, NOS }\end{array}$ & $*$ & & \\
\hline $\begin{array}{l}\text { Anaplastic oligodendroglioma, IDH-mutant and 1p/19q-codeledted } \\
\text { Anaplastic oligodendroglioma, NOS }\end{array}$ & & $*$ & \\
\hline $\begin{array}{l}\text { Oligoastrocytoma, NOS } \\
\text { Anaplastic oligoastrocytoma, NOS }\end{array}$ & $*$ & $*$ & \\
\hline
\end{tabular}

Table 4: Clinically relevant biomarkers in diffuse gliomas

\begin{tabular}{|c|c|c|c|c|c|}
\hline $\begin{array}{l}\text { Molecular } \\
\text { biomarker }\end{array}$ & Prevalence (\%) & Platform & Diagnostic & Prognostic & Predictive \\
\hline IDH mutation & $\begin{array}{l}\text { Oligo (II-III): } 100 \\
\text { Astro (II-III): } 70-80 \\
\text { Glioblastoma: } 8-10\end{array}$ & $\begin{array}{l}\text { IHC (IDH1) } \\
\text { DNA sequencing }\end{array}$ & + & + & \\
\hline 1p/19q-codeletion & Oligo (II-III): 100 & $\begin{array}{l}\text { PCR (LOH) } \\
\text { FISH (FFPE) }\end{array}$ & + & + & + \\
\hline ATRX mutation & $\begin{array}{l}\text { Astro: } \\
\text { Oligo: } 0\end{array}$ & $\mathrm{IHC}$ & + & & \\
\hline TP53 (p53) & $\begin{array}{l}\text { Astro: } 50 \\
\text { Oligo: } 10\end{array}$ & $\begin{array}{l}\text { IHC (- in Null mutation) } \\
\text { DNA sequencing }\end{array}$ & + & & \\
\hline $\begin{array}{l}\text { MGMT promoter } \\
\text { methylation }\end{array}$ & & PCR Pyrosequencing & & $+($ IDH asso $)$ & + \\
\hline $\begin{array}{l}\text { TERT promoter } \\
\text { mutation }\end{array}$ & Oligo and Glioblastoma & Sanger sequencing & & $+($ Other markers) & \\
\hline EGFR mutation & Glioblastoma: 40 & $\begin{array}{l}\text { FISH (EGFR amplification) } \\
\text { PCR sequencing (mutation) } \\
\text { IHC (EGFR vIII mutation) }\end{array}$ & + & & \\
\hline $\begin{array}{l}\text { BRAF V600E } \\
\text { mutation }\end{array}$ & Epithelioid glioblastoma: 50 & $\mathrm{IHC}$ & + & & \\
\hline H3 K27M mutation & Pons, thalamus SC & $\mathrm{IHC}$ & + & + & \\
\hline
\end{tabular}

and prognostic precision. ${ }^{2}$ WHO has given credence to three clinically relevant biomarkers identified in recent years which are $1 \mathrm{p} / 19 \mathrm{q}$ codeletion, mutations of isocitrate dehydrogenase (IDH 1 and 2) genes, and alpha thalassemia/ mental retardation syndrome X-linked gene (ATRX) gene. These three biomarkers have now been used to create a molecular diagnostic algorithm, which is found to be superior to the traditional histological approach. The family tree of the diffuse gliomas has been redrawn and is now organized under the common header of "Diffuse astrocytic and oligodendroglial tumors." Within this category, diffuse astrocytoma (WHO grade II) is stratified as IDH-mutant or IDH-wildtype with gemistocytic astrocytoma being IDH-mutant. Anaplastic astrocytoma (WHO grade III) is either IDH-mutant or IDH-wild type. Oligodendroglioma (WHO grade II) and anaplastic oligodendroglioma (grade III) are defined by the combined presence of IDH mutation and $1 \mathrm{p} / 19 \mathrm{q}$ codeletion. The suffix "NOS" (Not Otherwise Specified) is used when relevant molecular tests cannot be done or are only partially performed. Diffuse gliomas with overlapping morphological features (mixed oligoastrocytoma) will now be a rarity because it requires the presence of molecular and genetic signatures of both astrocytoma and oligodendroglioma in separate areas of 


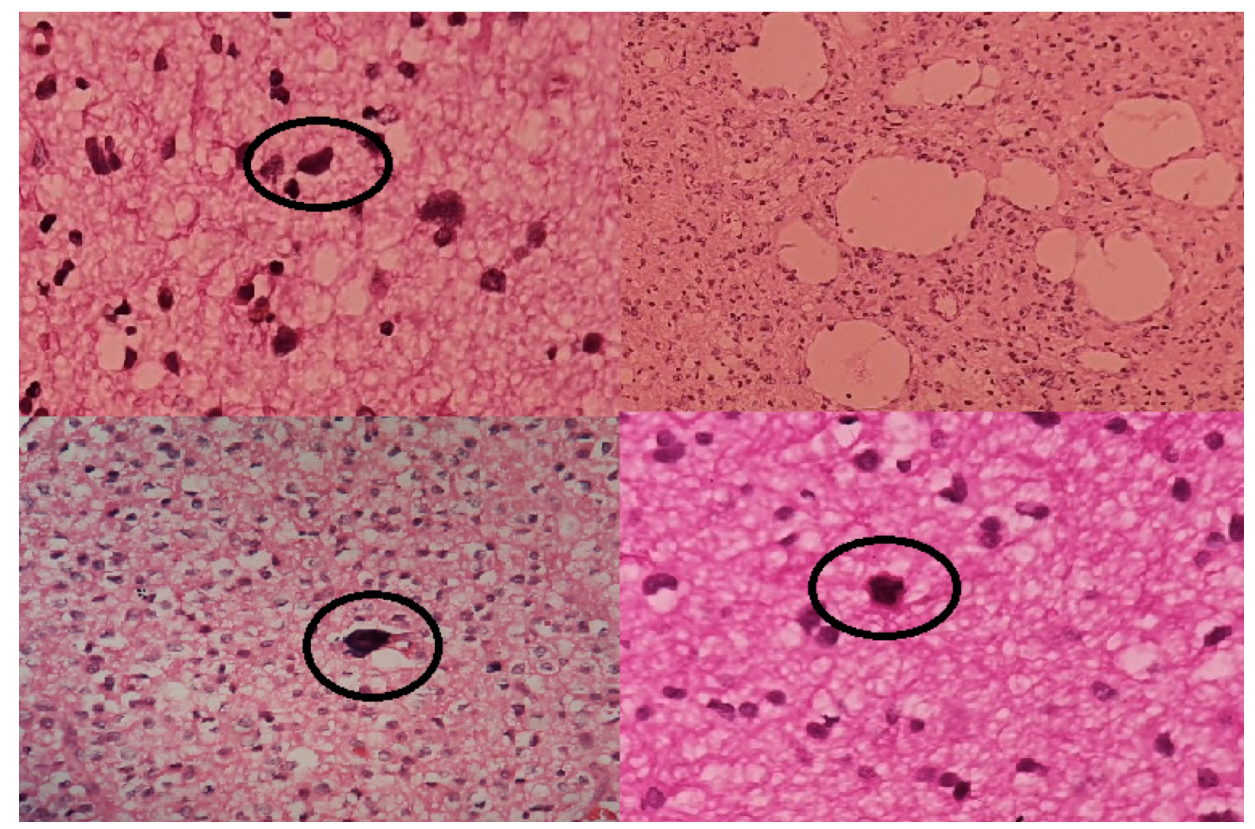

Figure 1: Glioma versus gliosis. The presence of enlarged hyperchromatic nuclei (top left, circled), microcysts (top right), calcifications (bottom left, cricled) and mitotic figures (bottom right, circled) are important for the histological diagnosis of glimoas. (HEx100: Top right and bottom left; HEx400: Top left and bottom right).

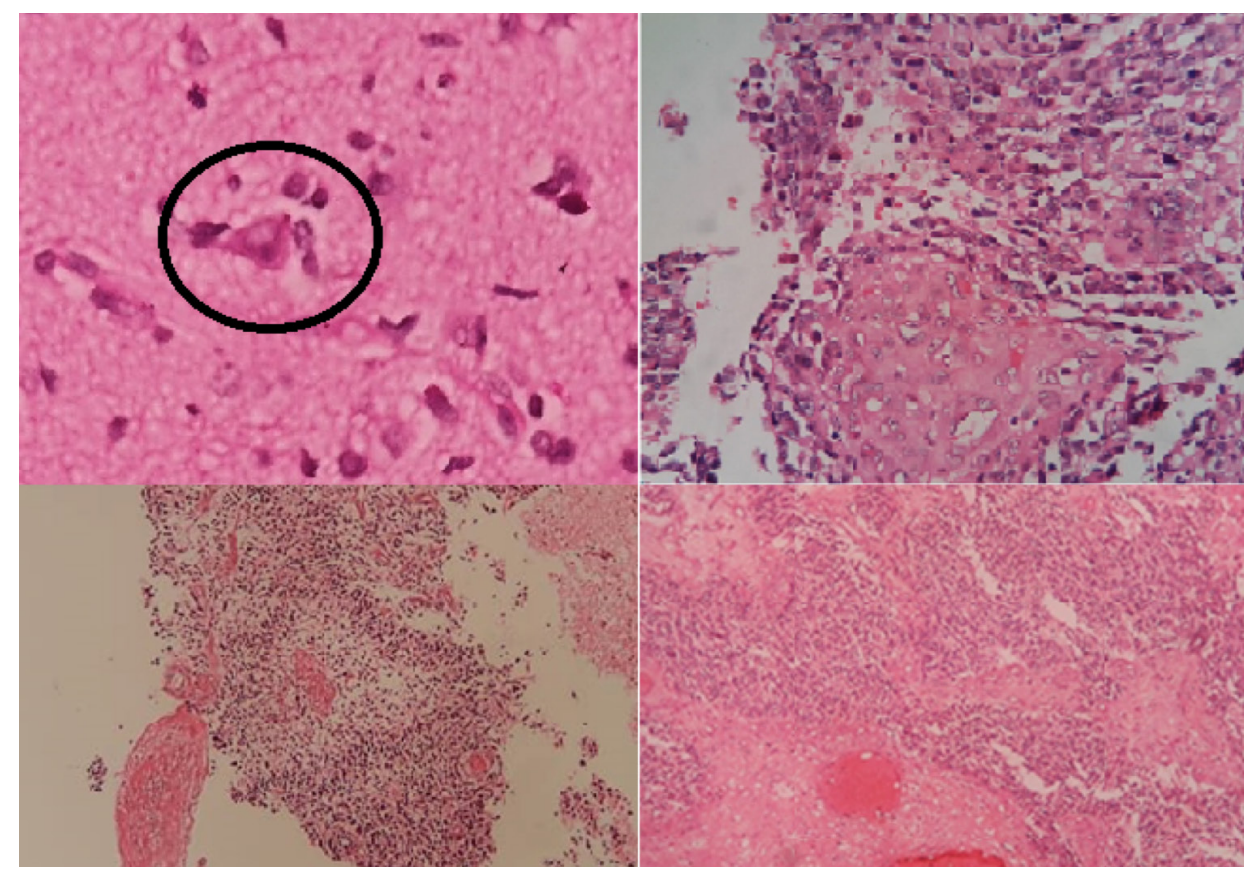

Figure 2: Features of diffuse and higher grade gliomas. Perineuronal satellitosis (top left, circled), mircovascular proliferation (top right), pseudopalisading necrosis (bottom left) and ischaemic necrosis (bottom right) characterize the diffuse nature of the neoplasm and higher grades of the tumor. (HEx400: Top left; HEx100 Rest)

the tumour. Glioblastoma (WHO grade IV) is now also classified according to IDH status as glioblastoma, IDHmutant and glioblastoma, IDH-wildtype. The histological variants of glioblastoma, IDH-wildtype include giant cell glioblastoma, gliosarcoma and epithelioid glioblastoma. NOS designation can be applied in cases where molecular tests are not done or are incomplete. Protoplasmic and fibrillary astrocytoma variants of diffuse astrocytoma have been deleted from the WHO 2016 classification. The tumour entity gliomatosis cerebri has also been removed. A new entity that has been added in the new classification is diffuse midline glioma, H3 K27M-mutant (Table 3). 


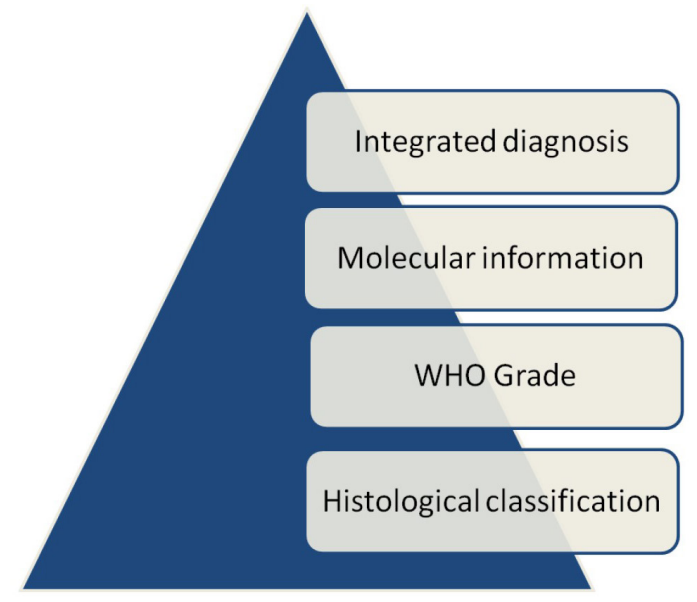

Figure 3: The layered diagnostic format for diffuse gliomas

\section{CLINICALLY RELEVANT MOLECULAR MARKERS OF DIFFUSE GLIOMAS}

\section{Isocitrate dehydrogenase (IDH) mutation}

Isocitrate dehydrogenase (IDH) 1 and 2 mutations are seen mainly in diffuse grade II and III gliomas and to a lesser extent in glioblastoma.10 IDH is an essential enzyme in the citric acid cycle, which catalyzes the oxidative decarboxylation of isocitrate to alpha ketaglutarate. Of the IDH mutations found found in gliomas, the vast majority are in IDH1, the commonest being IDH1 (R132H). IDH 2 mutation frequently leads to alteration in arginine at position 172. ${ }^{11}$ These IDH mutations are thought to be important initial players in gliomagenesis. ${ }^{12}$ The IDH mutations are seen in $100 \%$ of oligodendroglioma and $70 \%-80 \%$ of WHO grade II and III astrocytomas. ${ }^{13}$ Only $8 \%-10 \%$ of glioblastomas are IDH-mutant. The IDHmutant gliomas have a better prognosis than their wildtype counterparts irrespective of their histological grade. ${ }^{10}$ Immunohistochemistry (IHC) is the most prevalent and a very robust method to demonstrate IDH1 (R132H) mutant protein and showed 100\% concurrence with sequencing for IDH1 (R132H). ${ }^{14}$ However, other IDH1 and IDH2 mutations can be tested by DNA sequencing only. Thus, all cases of diffuse gliomas should be first evaluated by IHC for IDH1 (R132H), and only those that are negative by IHC can be subjected to deoxyribonucleic acid (DNA) sequencing for detection of other IDH1 and IDH2 mutations. However, direct evaluation for all IDH1 and IDH2 mutations by DNA sequencing without the initial IHC can also be done, where feasible.

\section{1p/19q-codeletion}

Unbalanced translocation between the short arm of chromosome 1 and long arm of chromosome 19 with subsequent loss of the derivative chromosome, del $(1 ; 19)$ (p10; q10), is seen in oligodendrogliomas. ${ }^{15}$ Codeletion of these chromosome arms is a specific molecular alteration and is now a mandatory requirement for the diagnosis of oligodendroglioma. This alteration is associated with improved survival and also serves as a predictor of sensitivity to chemotherapy. ${ }^{16}$ Hence, $1 \mathrm{p} / 19 \mathrm{q}$ codeletion is used as a potential diagnostic, prognostic, and predictive marker in oligodendroglial tumors. The genes on $1 \mathrm{p}$ and 19 that are

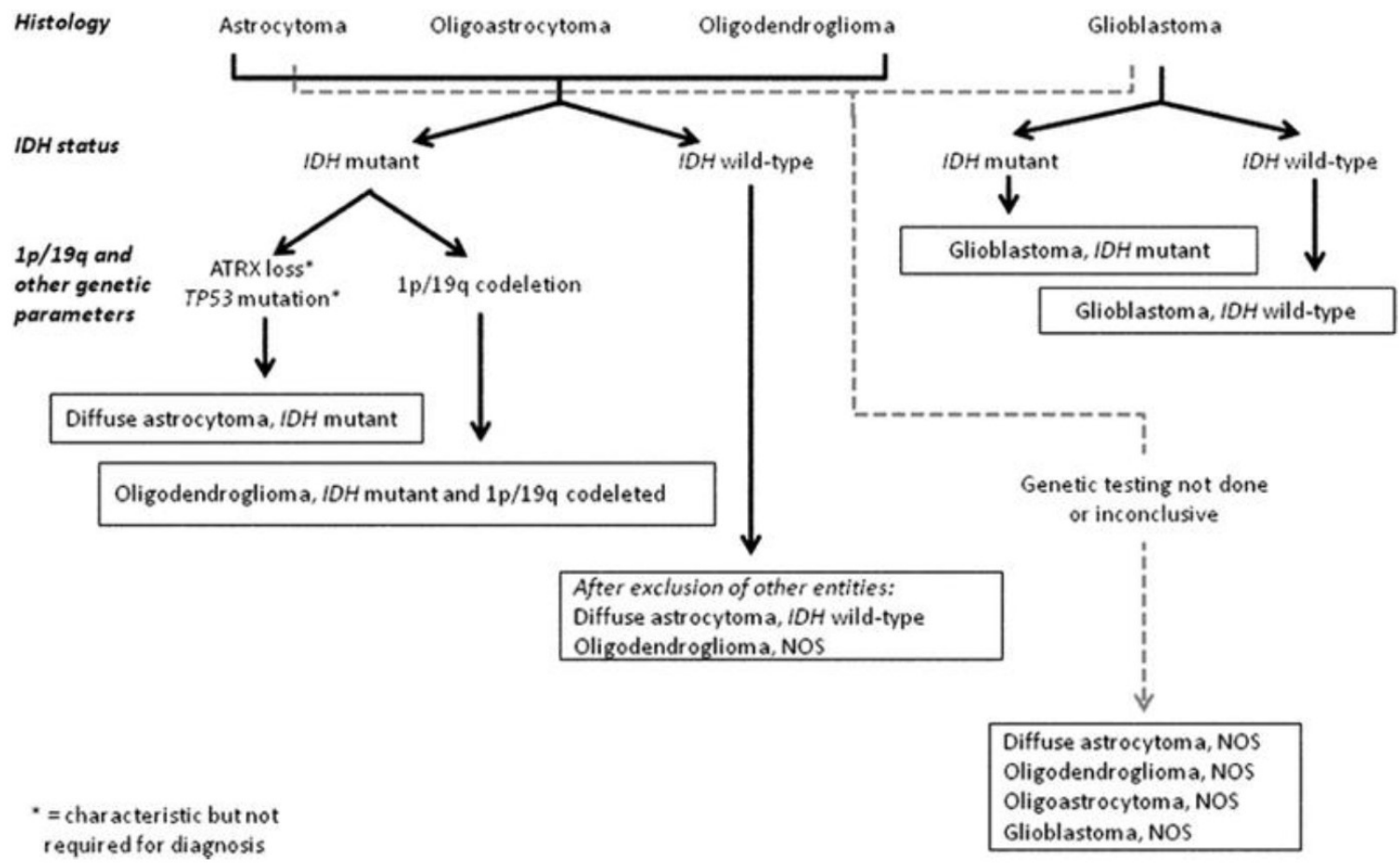

Figure 4: Diffuse gliomas: From histology, IDH status, and other genetic paramters to WHO diagnosis ${ }^{2}$ 


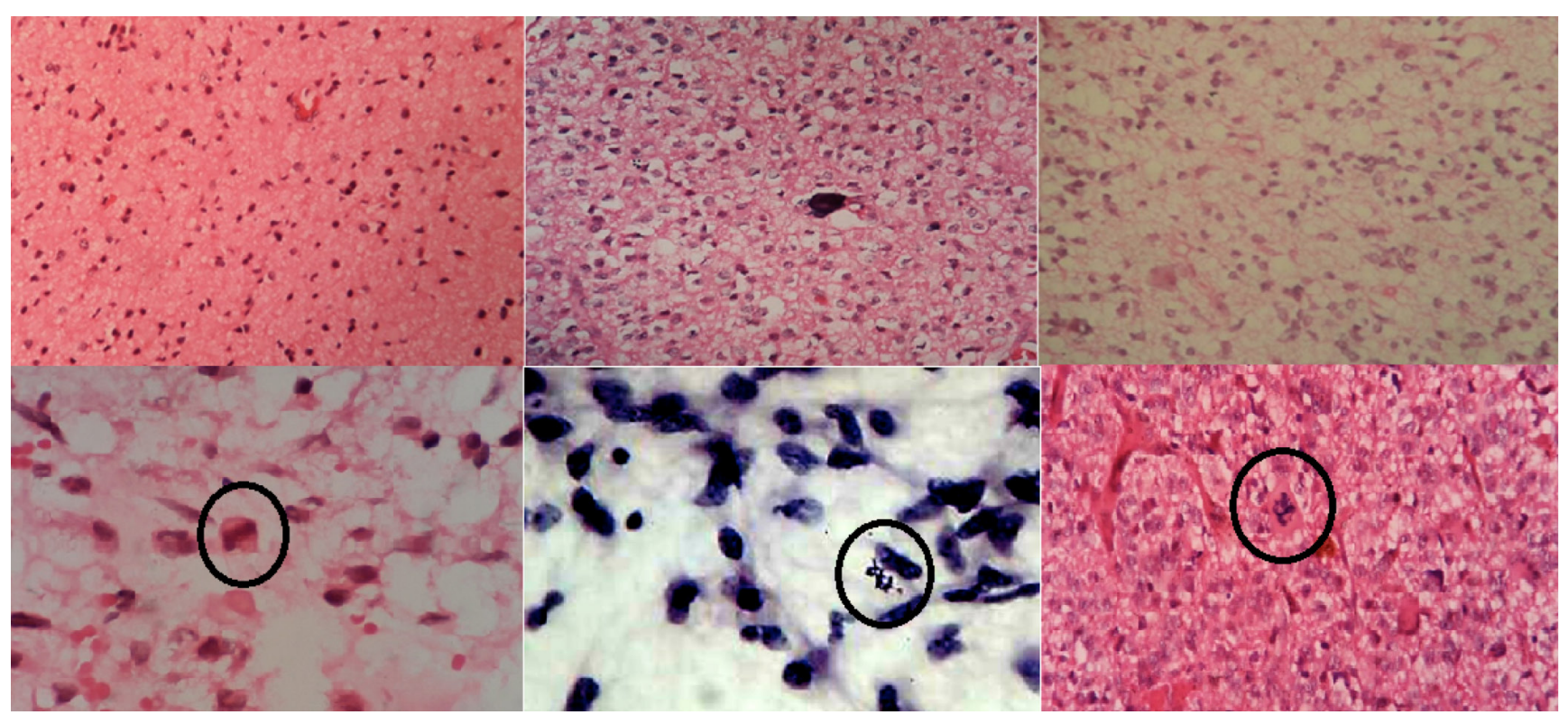

Figure 5: Histological features of astrocytoma, oligodendroglioma and oligoastrocytoma. Angulated cells of astrocytoma (top left), perinuclear halos and microcalcification of oligodendroglioma (top centre) and a mixture of round and angulated cells of oligoastrocytoma (top right). Mitotic figures characterize high grade tumours (Bottom, mitotic figures circled). All tissue sections except bottom centre which is intraoperative cytology smear. (HEx100: Top row; HEx1000: Bottom row).

thought to be responsible for the effect of $1 \mathrm{p} / 19 \mathrm{q}$-codeletion are FUBP1 and CIC, respectively. Over the years, 1p/19q codeletion has been evaluated by polymerase chain reaction (PCR) based loss of heterozygosity, fluorescent in situ hybridization (FISH) and next generation sequencing (NGS) platforms. However, the currently preferred technique for assessing $1 \mathrm{p} / 19 \mathrm{q}$ codeletion is the FISH technique owing to the ease of availability of commercial target probes and feasibility to perform the test on formalin-fixed paraffin embedded (FFPE) tissue sections.

\section{Alpha Thalassemia Mental Retardation X-linked gene (ATRX) mutation}

Alpha Thalassemia Mental Retardation X-linked gene (ATRX) is involved in chromatin remodeling, histone regulation, nucleosome assembly and maintenance of telomeres. Mutations in this gene, located at Xq210. lead to loss of function. The ATRX mutation is reliably detected by IHC where a tumor with the mutation is immunonegative for ATRX protein, and positivity is seen in native glial / microglial cells, neurons, inflammatory cells, and endothelial cells which serve as internal quality control for proper staining. Mutations in ATRX have a strong correlation with tumors of astrocytic phenotype that harbour TP53 and IDH mutations. ${ }^{17}$ ATRX mutation is not seen in any oligodendroglial tumors and is mutually exclusive with $1 \mathrm{p} / 19 \mathrm{q}$ codeletion. It is presumed that ATRX mutation follows IDH mutation during astrocytoma tumorigenesis.

\section{TP53 mutation}

TP53 is an essential regulator of the cell cycle, forming a part of the tumor suppressor gene family. The TP53 gene provides instructions for making a protein called tumor protein p53 (or p53) that acts as a tumor suppressor. TP53 mutations are found to be almost mutually exclusive with $1 \mathrm{p} / 19 \mathrm{q}$-codeletion in gliomas and correlate strongly with an astrocytic morphology. ${ }^{18}$ Approximately $50 \%$ of astrocytomas harbor TP53 mutations, in contrast to just $10 \%$ of oligodendrogliomas. As TP53 mutations show a close relationship to ATRX mutations and IDH mutations, co-existence of these three mutations can be viewed as a molecular signature of astrocytomas. ${ }^{19}$ On IHC, p53 protein accumulation is detected as positive staining of the nuclei and serves as a surrogate marker for detection of the mutation. Null mutations will not be detected by IHC as the protein is absent. In addition, immunopositivity for $\mathrm{p} 53$, while highly concordant with Tp 53 mutation, cannot always be taken as concrete proof of mutation. DNA sequencing is the gold standard to detect the presence of a TP53 mutation in a particular sample.

\section{O6-methylguanine DNA methyltransferase promoter (MGMT) methylation}

O6-methylguanine DNA methyltransferase (MGMT) is a DNA repair protein enzyme encoded by the MGMT gene located at 10q26. MGMT repairs DNA crosslinks and prevents cell death by removing alkyl groups from the O6 position of guanine. The enzyme ensures rapid repair of DNA, making a cell more resistant to temozolomide, the principal chemotherapeutic alkylating agent used in glioma treatment. ${ }^{20}$ Epigenetic silencing of this gene by promoter methylation increases the susceptibility of gliomas to temozolomide by inducing apoptotic cell death and is also an independent prognostic marker regardless of the type of treatment. ${ }^{21}$ Although some studies have suggested that 


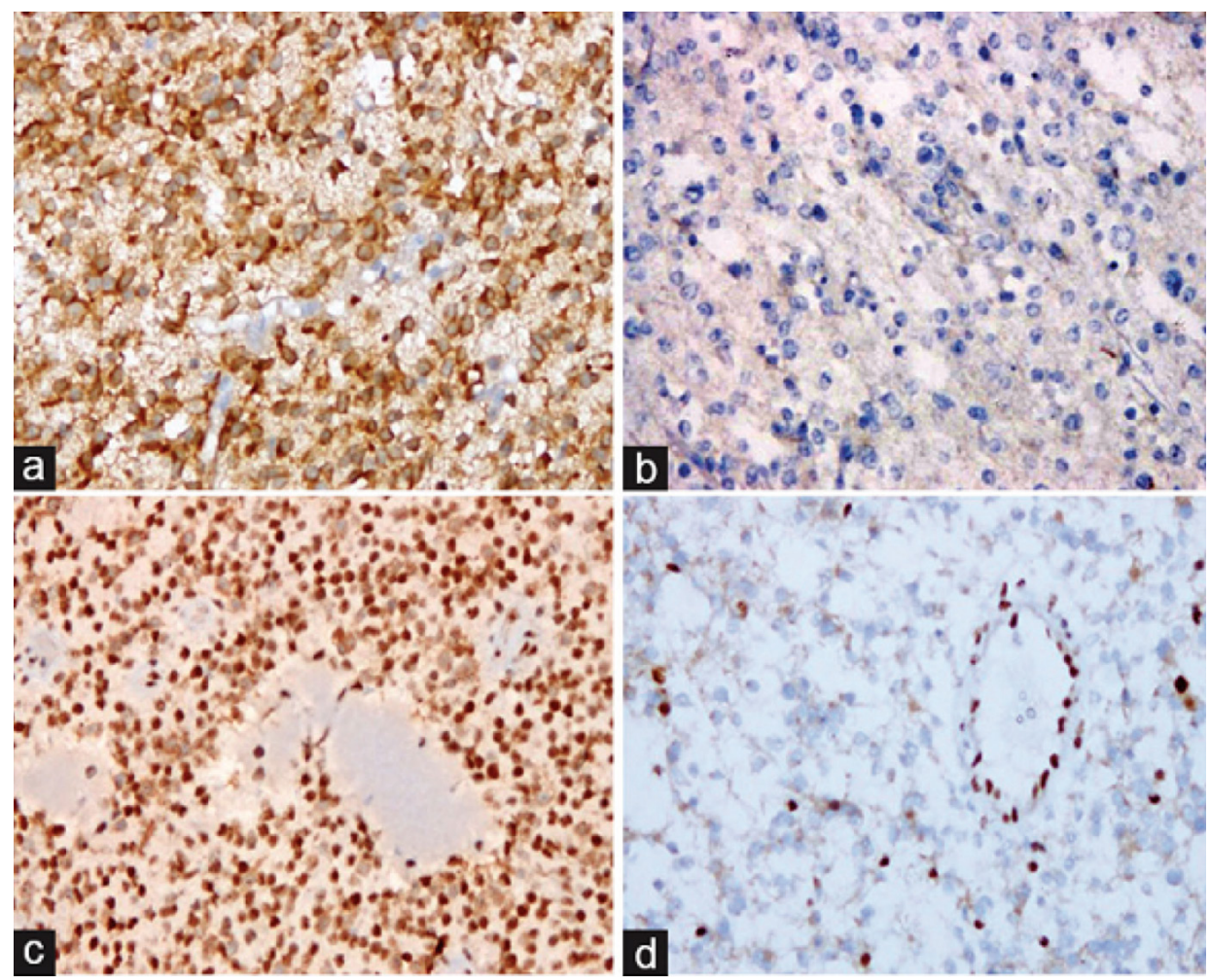

Figure 6: IHC for IDH1 and ATRX. Representative images of (a) IDH1 (R132H) immunopositive glioma, (b) IDH1 (R132H) immunonegative glioma, (c) ATRX retained glioma (non-mutated) and (d) glioma showing loss of expression of ATRX (mutated). (All images X400) ${ }^{34}$
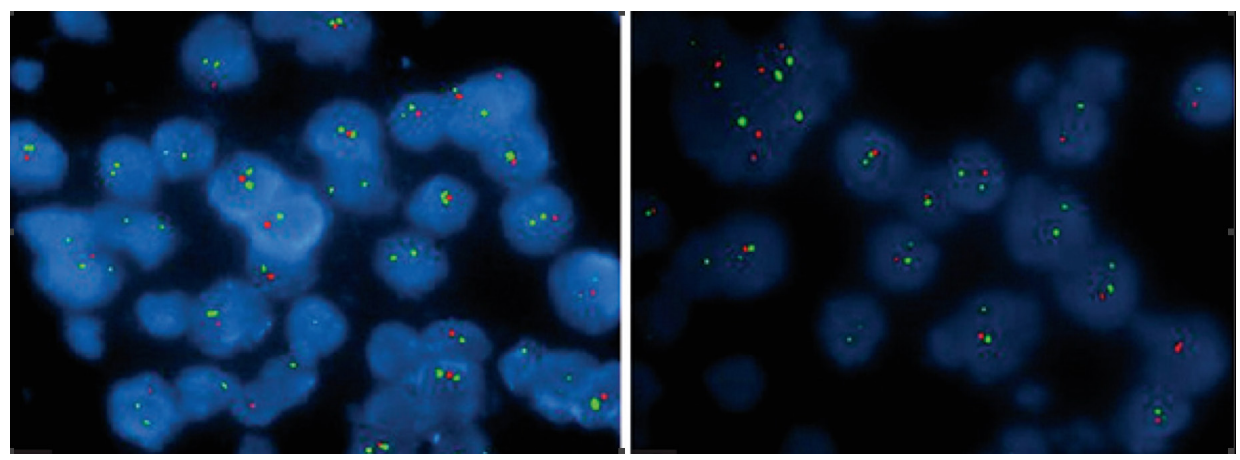

Figure 7: FISH for 1p / 19q-codeletion. Oligodendroglioma showing 1p and 19q-codeletion by FISH ${ }^{34}$

the prognostic power of MGMT promoter methylation is derived from its close association with the IDH mutation, other studies have observed that the methylation status of the MGMT promoter is a predictive marker of the response to chemotherapy in IDH-wildtype tumors as well. ${ }^{22,23}$ MGMT promoter methylation is commonly assessed by methylation specific PCR (conventional or real-time) and pyrosequencing.

\section{Telomerase reverse transcriptase (TERT) promoter mutation}

In recent years, although telomerase reverse transcriptase (TERT) promoter mutations have been actively studied as mutations that are quite prevalent in gliomas as well as being significantly associated with survival and prognosis, the nature of this association depends in a large part upon the presence of other molecular alterations. ${ }^{24,25}$ The significance of TERT promoter mutations in IDH-wildtype glioblastoma remains controversial. However, the analysis of other molecular markers alongside TERT promoter mutations may better define prognostic subgroups in gliomas. ${ }^{25}$ The TERT promoter mutations are detected by DNA sequencing. Epidermal growth factor receptor (EGFR) gene
mutation

One of the most common mutations that occur in IDHwildtype glioblastomas is the gain of $7 p$, harboring the epidermal growth factor receptor (EGFR) gene. ${ }^{26}$ About $40 \%$ of glioblastomas carry this mutation. The EGFR gene codes for a cell surface tyrosine kinase receptor that initiates the PI3K and MAPK pathways, which contribute to cell survival and proliferation. The most common EGFR gene 


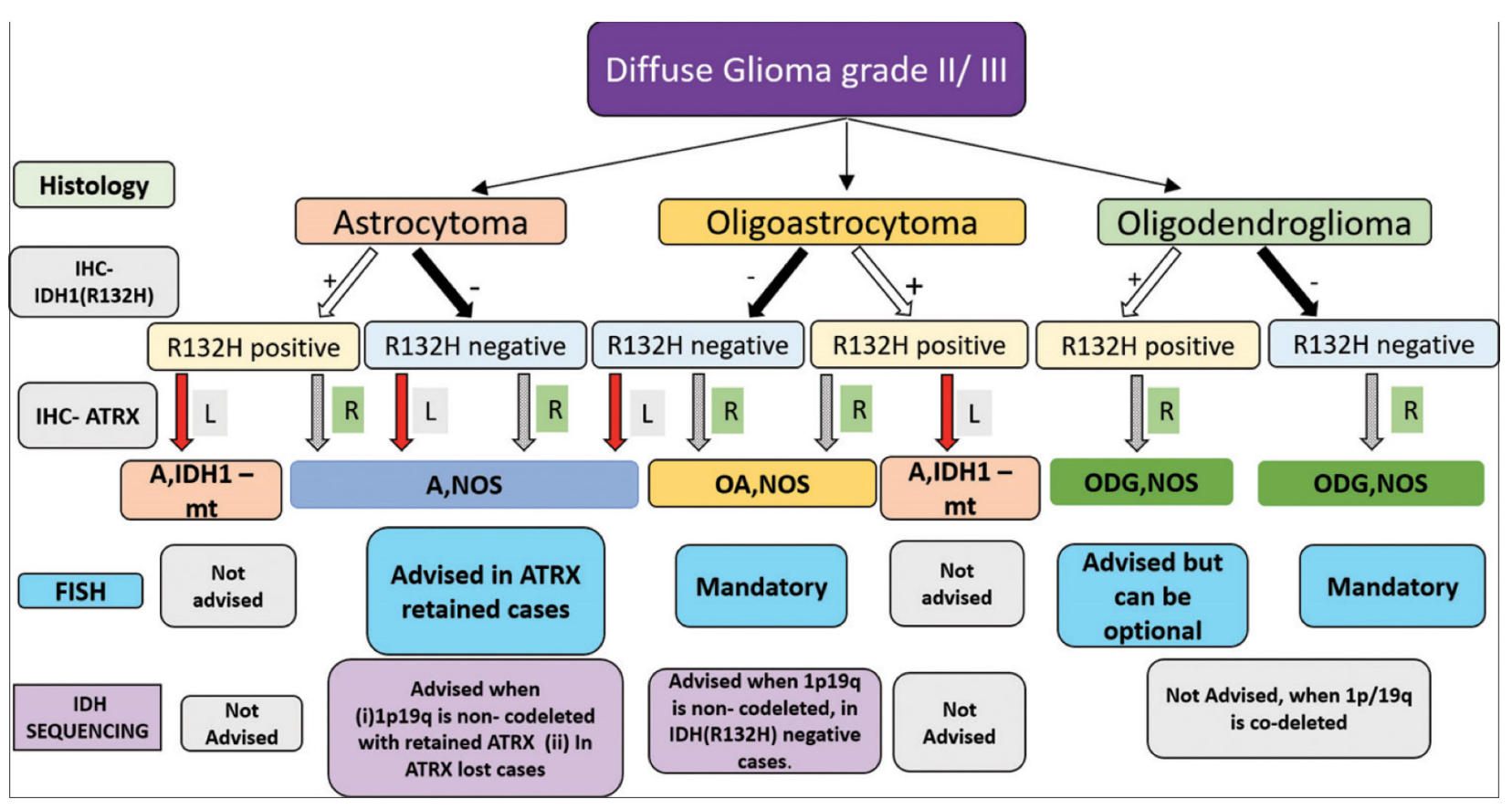

Figure 8: ISNO algorithm for diagnosis of WHO grade II and grade III diffuse gliomas in a resource limited setting ${ }^{34}$

aberration encountered in glioblastoma is its amplification. A proportion of the EGFR amplified tumors carry the EGFR vIII mutation, which plays a significant role in gliomagenesis, increasing the survival of the mutant cells as well as adjacent cells through paracrine activity. ${ }^{27}$ The EGFR amplification can be assessed by the FISH technique. The presence or absence of the EGFR mutation can be detected by IHC using antibodies to EGFR vIII, or by PCR sequencing. ${ }^{28}$

\section{BRAFV600E mutation}

BRAFV600E mutation has been described frequently in circumscribed gliomas like pleomorphic xanthoastrocytoma (PXA) and less often in diffuse adult gliomas. ${ }^{29}$ Approximately, 50\% of cases of epithelioid glioblastoma harbor this mutation. 30 The survival implication of this mutation is not well established to date with the few case reports suggesting a variable prognosis. BRAFV600E mutation can be detected using IHC.

\section{Histone (H3 K27M) mutation}

Histone protein $\mathrm{H} 3$ is one of the four proteins essential for the formation of octamer complex around which the DNA is wrapped to form a nucleosome. Diffuse midline gliomas often harbor mutation in the $\mathrm{H} 3$ protein. These are infiltrative midline gliomas characterized by $\mathrm{K} 27 \mathrm{M}$ mutation in either H3F3A or HIST1H3B/C genes. ${ }^{2}$ Mutation occurring in either $\mathrm{H} 3.1$ or $\mathrm{H} 3 .^{3}$ protein leads to $\mathrm{H} 3 \mathrm{~K} 27 \mathrm{M}$ mutation, which prevents the methylation/acetylation of lysine at position 27. Trimethylated H3K27 (H3 K27Me3) is essential for tumor suppression and differentiation. Thus,
H3 K27M-mutant diffuse midline gliomas show a decrease in $\mathrm{H} 3 \mathrm{~K} 27 \mathrm{Me} 3$, which confers very poor prognosis to these tumors. ${ }^{31} \mathrm{H} 3 \mathrm{~K} 27 \mathrm{M}$-mutant protein can be detected by IHC. The mutation, while commonly present in diffuse midline gliomas, may also be present in gliomas in other locations. However, the Consortium to Inform Molecular and Practical Approaches to CNS Tumor Taxonomy- Not Official WHO (cIMPACT-NOW) working group has clarified that only those diffuse gliomas located in the midline and positive for $\mathrm{H} 3 \mathrm{~K} 27 \mathrm{M}$ are to be designated as "diffuse midline glioma, H3 K27M-mutant." 32

The clinically relevant biomarkers are summarized in Table 4.

\section{PROLIFERATIVE INDEX}

The proliferative index as measured by Ki-67 labelling index has a controversial reputation as a reliable biologic marker to properly correlate with histological grade for prognostication of diffuse gliomas. ${ }^{2}$ However, it can be used to validate the mitotic count and some studies have enforced its value as a useful adjunct to histopathological grading of astrocytomas. ${ }^{33}$ WHO grade II, III and IV diffuse gliomas typically have a proliferation index of less than $5 \%, 5-10 \%$ and $15-20 \%$, respectively. $^{2}$

\section{THE LAYERED HISTO-MOLECULAR DIAGNOSIS OF DIFFUSE GLIOMAS}

2016 WHO classification recommends a layered histomolecular diagnosis of diffuse gliomas with histological diagnosis and WHO grade provided on H\&E sections to be 


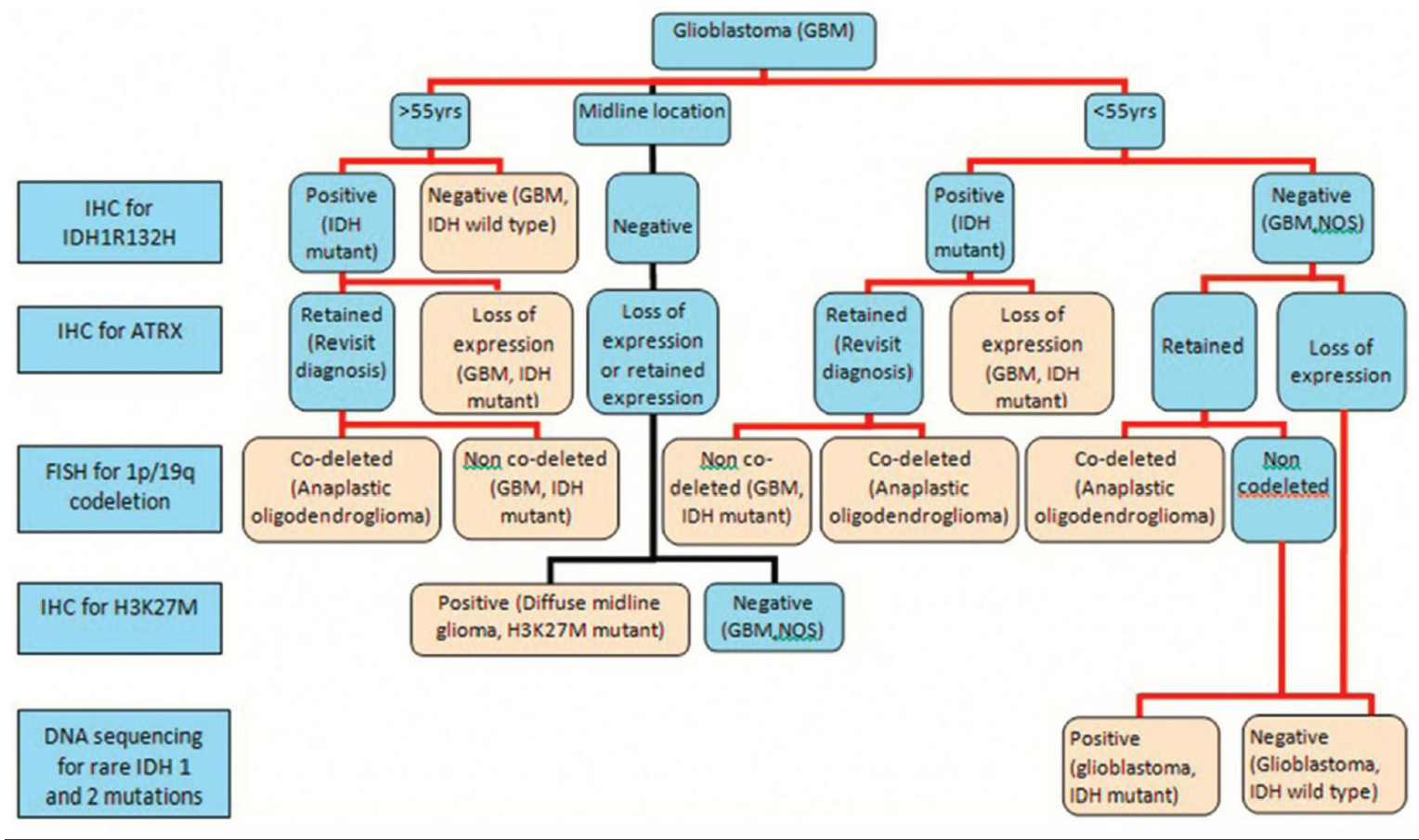

Figure 9: ISNO algorithm for diagnosis of glioblastoma in a resource limited setting ${ }^{34}$

supplemented by molecular characterization of the lesion to generate an integrated diagnosis (Fig. 3).

It is now mandatory to analyze for the IDH mutational and $1 \mathrm{p} / 19 \mathrm{q}$ codeletion status in all diffuse gliomas for their complete workup (Fig. 4). ATRX loss and TP53 mutation are characteristic of but are not required for the diagnosis of astrocytoma

\section{IMPLEMENTATION OF THE WHO PROTOCOL IN RESOURCE LIMITED SETUP}

The WHO 2007 classification based on histomorphology on $\mathrm{H} \& \mathrm{E}$ stained slides alone allowed for providing a definitive diagnosis in diffuse gliomas within a few days after surgery. The requirement of an integrated diagnosis based on molecular testing as per updated 2016 WHO classification extends the time to a few weeks. Incorporation of integrated diagnosis into routine clinical practice increases cost for the patient and is dependent on the number of molecular markers tested, assays / methods used for such molecular testing, total number of samples tested, and of course, the health-care setting. The cost of these tests is generally not affordable by patients from the lower economic strata. In Nepal where even IHC is available in only select healthcare centres because of lack of both resource and trained manpower, the routine use of molecular markers is very difficult. Even in India, whilst IHC for IDH1 (R132H), ATRX, and P53 is available in most of the diagnostic histopathology laboratories, FISH and DNA sequencing techniques are offered only in major diagnostic / research centers. ${ }^{34}$ In keeping with all the above issues, the Indian
Society of Neuro-oncology (ISNO) realized the need and recommended a practical, economical, working algorithm for the integrated diagnosis of diffuse gliomas that suits a resource constraint environment. ISNO adapted the WHO 2016 classification to recommend a more practical and pragmatic approach by suggesting IHC for ATRX in addition to IDH1 mutation for classification of adult diffuse gliomas. This has also been further clarified by the cIMPACT-NOW35 which suggests that diffuse astrocytic tumors that are WHO grade II or grade III and that have IDH mutation can be diagnosed as diffuse astrocytoma, IDH-mutant or anaplastic astrocytoma, IDH-mutant, respectively, if there is definite loss of ATRX nuclear expression and/or strong, diffuse p53 immunopositivity, without the need for $1 \mathrm{p} / 19 \mathrm{q}$ testing. ${ }^{32}$ The guidelines are framed for adult diffuse gliomas (WHO Grades II and III) as well as glioblastoma (grade IV) and its variants and provide details of the required histological and molecular work-up.

The salient features of the ISNO guidelines for WHO grades II / III diffuse gliomas are as follows:

1. Microscopical assessment of the diffuse glioma categorizes it according to phenotypical histological characteristics as Astrocytoma, Oligoastrocytoma, Oligodendroglioma (Fig. $5)$.

2. IHC for IDH1 and ATRX is performed in all cases of diffuse gliomas and the result categorizes the diffuse glioma into the following four subgroups: Astrocytoma-IDHmutant, astrocytoma-NOS, oligoastrocytoma-NOS and 
oligodendroglioma-NOS (Fig. 6).

3. FISH testing for $1 \mathrm{p} / 19 \mathrm{q}$-codeletion is not advised in astrocytoma, IDH-mutant cases. ${ }^{35}$ It is not mandatory for Oligodendroglioma, NOS cases with classical oligodendroglioma morphology that are IDH1 positive and ATRX retained because previous studies, including that of Rajeswari et al, have shown that all (100\%) such cases show $1 \mathrm{p} / 19 \mathrm{q}$-codeletion. ${ }^{36}$ FISH for $1 \mathrm{p} / 19$ status becomes mandatory in the following groups:

a. Oligodendrogliomas, NOS cases that are IDH1 negative by IHC because it is possible that some of these tumors could be other gliomas that morphologically mimic oligodendroglioma

b. Oligoastrocytoma-NOS cases, as this group encompasses both $1 \mathrm{p} / 19$-codeleted and non-codeleted tumors, and

c. Astrocytoma- NOS cases that show ATRX retained status (fig. 7).

4. DNA sequencing for rare IDH mutations is mandatory in the astrocytoma and oligoastrocytoma tumors that are negative for IDH1 by IHC and show 1p/19q non-codeleted status.

The algorithm for diagnosis of WHO grade II and grade III diffuse gliomas in a resource limited setting is shown in Figure 8 .

The main points in ISNO guidelines for the diagnosis of glioblastoma (WHO grade IV) are as follows (fig. 9):

1. Glioblastoma is histologically diagnosed with the presence of microvascular proliferation and / or necrosis in a diffuse glioma. A particular variant of glioblastoma is determined on the basis of histomorphology and certain variants may demand testing for a specific molecular marker, for example, BRAFV600E mutation for epitheloid glioblastoma.

2. IHC for IDH1 stratifies patients older than 55 years into glioblastoma, IDH-mutant or glioblastoma, IDH-wildtype. For patients 55 years or younger, IDH1 categorizes patients into glioblastoma, IDH-mutant or glioblastoma, NOS. IHC for ATRX is performed in all cases and is typically lost in glioblastoma, IDH-mutant cases. In glioblastoma NOS, ATRX immunostaining provides valuable insight into the possible rare IDH mutation status. IHC for H3 K27M is required in addition to IDH and ATRX mutation if the location of the lesion is in the midline.

3. FISH for $1 \mathrm{p} / 19 \mathrm{q}$-codeletion is mandatory for all cases with ATRX retention because the presence of codeletion categorizes the lesion as anaplastic oligodendroglioma, IDH-mutant and 1p/19q-codeleted.
4. DNA sequencing for rare IDH mutations is recommended in glioblastoma only in two scenarios in a young patient, that is, when IDH1 is negative, ATRX is retained and $1 p / 19 q$ is non-codeleted or when IDH1 is negative and ATRX is lost.

\section{CONCLUSION}

WHO 2016 classification reorganizes diffuse gliomas into a more meaningful framework by grouping them according to their molecular characteristics and the completeness of our evaluation in an individual case. It continues to recognize the contribution of histological assessment to properly categorize and grade diffuse gliomas before recommending further testing to generate an integrated diagnosis incorporating molecular information. This new approach not only eliminates inter-observer variability in histological diagnosis, but also provides more robust parameters to better prognosticate these tumours and to better predict their response to treatment. While implementing the recommendations in our resource limited setups, it is both necessary and practical to devise our own algorithm based on new scientific data and recommendations that our deserving patients can afford.

\section{Acknowledgement}

I wish to dedicate this article to the ever empowering memories of our Prof Upendra Prasad Devkota, the pioneer neurosurgeon of Nepal.

\section{Conflict of Interest: None}

\section{REFERENCES}

1. Peiffer J, Kleihues P. Hans-Joachim Scherer (1906-1945), pioneer in glioma research. Brain Pathol 1999 Apr; 9(2):241-5. Crossref

2. Louis DN, Ohgaki H, Wiestler OD, Cavenee WK, editor. WHO Classification of Tumors of the Central Nervous System, Revised 4t. France: International Agency for Research on Cancer (IARC); 2016. Crossref

3. Van den Bent MJ. Interobserver variation of the histopathological diagnosis in clinical trials on glioma: a clinician's perspective. Acta Neuropathol 2010; 120(3): 297-304. Crossref

4. Wang J, Hu G, Quan X. Analysis of the factors affecting the prognosis of glioma patients. Open Med (Wars) 2019;14:331-5. Crossref

5. Upadhyay N, Waldman AD. Conventional MRI evaluation of gliomas. Br J Radiol 2011 Dec; 84 (Spec Iss 2): S107-11. Crossref

6. Villaneueva-Meyer JE, Wood MD, Choi BS et al. MRI features and IDH mutational status of grade II diffuse gliomas: impact on diagnosis and prognosis. Am J Roentgenol 2018; 210(3): 621-8. Crossref 
7. Lacroix M, Toms SA. Maximum safe resection of glioblastoma multiforme. J Clin Oncol 2014; 32:727-8. Crossref

8. Jakola AS, Skjulsvik AJ, Myrmel KS, et al. Surgical resection versus watchful waiting in low-grade gliomas. Ann Oncol 2017;28:1942-8. Crossref

9. Vuorinen V, Hinkka S, Färkkilä M, et al. Debulking or biopsy of malignant glioma in elderly people-a randomised study. Acta Neurochir (Wien) 2003;145: 5-10. Crossref

10. Cohen AL, Holmen SL, Colman H. IDH1 and IDH2 mutations in gliomas. Curr Neurol Neurosci Rep 2013;13:345. Crossref

11. Yan H, Parsons W, Jin G, McLendon R, Rasheed A et al. IDH1 and IDH2 mutations in gliomas. N Engl J Med 2009;360:765-73. Crossref

12. Watanabe T, Nobusawa S, Kleihues P et al. IDH1 mutations are early events in the development of astrocytomas and oligodendrogliomas. Am J Pathol 2009;174:1149-53. Crossref

13. Balss J, Meyer J, Mueller W et al. Analysis of the IDH1 codon 132 mutation in brain tumors. Acta Neuropathol 2008;116:597-602. Crossref

14. Agarwal S, Sharma MC, Jha P et al. Comparative study of IDH1 mutations in gliomas by immunohistochemistry and DNA sequencing. Neuro Oncol 2013;15:718-26. Crossref

15. Yip S, Butterfield YS, Morozova O et al. Concurrent CIC mutations, IDH mutations, and 1p/19q loss distinguish oligodendrogliomas from other cancers. J Pathol 2012;226:7-16. Crossref

16. Cairncross JG, Ueki K, Zlatescu MC et al. Specific genetic predictors of chemotherapeutic response and survival in patients with anaplastic oligodendrogliomas. J Natl Cancer Inst1998;90:1473-9. Crossref

17. Liu X-Y, Gerges N, Korshunov A et al. Frequent ATRX mutations and loss of expression in adult diffuse astrocytic tumors carrying IDH1/IDH2 and TP53 mutations. Acta Neuropathol 2012;124:61525. Crossref

18. Gillet E, Alentorn A, Doukouré B et al. TP53 and p53 statuses and their clinical impact in diffuse low grade gliomas. J Neurooncol 2014;118:131-9. Crossref

19. Li X, Wei J, Liu Y et al. Primary astrocytic tumours and paired recurrences have similar biological features in IDH1, TP53 and TERTp mutation and MGMT, ATRX loss. Sci Rep 2017;7. Crossref

20. Hegi ME, Diserens A-C, Gorlia T et al. MGMT gene silencing and benefit from temozolomide in glioblastoma. N Engl $\mathrm{J}$ Med 2005;352:997-1003. Crossref

21. Van den Bent MJ, Dubbink HJ, Sanson M et al. MGMT promoter methylation is prognostic but not predictive for outcome to adjuvant PCV chemotherapy in anaplastic oligodendroglial tumors: A report from EORTC Brain Tumor Group Study 26951. J Clin Oncol
2009;27:5881-6. Crossref

22. Wick W, Hartmann C, Engel C et al. NOA-04 randomized phase III trial of sequential radiochemotherapy of anaplastic glioma with procarbazine, lomustine, and vincristine or temozolomide. J Clin Oncol2009;27:5874-80. Crossref

23. Van den Bent MJ, Erdem-Eraslan L, Idbaih A et al. MGMT-STP27 methylation status as predictive marker for response to $\mathrm{PCV}$ in anaplastic oligodendrogliomas and oligoastrocytomas. A report from EORTC study 26951. Clin Cancer Res 2013;19:5513-22. Crossref

24. Killela PJ, Reitman ZJ, Jiao Y et al. TERT promoter mutations occur frequently in gliomas and a subset of tumors derived from cells with low rates of self-renewal. Proc Natl Acad Sci USA 2013;110:6021-6. Crossref

25. Eckel-Passow JE, Lachance DH, Molinaro AM et al. Glioma groups based on 1p/19q, IDH, and TERT promoter mutations in tumors. N Engl J Med2015;372:2499-508. Crossref

26. Chaffanet $\mathrm{M}$, Chauvin $\mathrm{C}$, Liane $\mathrm{M}$ et al. EGF receptor amplification and expression in human brain tumours. Eur J Cancer 1992;28:11-7. Crossref

27. Heimberger AB, Suki D, Yang D et al. The natural history of EGFR and EGFRvIII in glioblastoma patients. J Transl Med 2005;3:38. Crossref

28. Aldape KD, Ballman K, Furth A et al. Immunohistochemical detection of EGFRvIII in high malignancy grade astrocytomas and evaluation of prognostic significance. J Neuropathol Exp Neurol 2004;63:700-7. Crossref

29. Appin CL, Brat DJ. Molecular genetics of gliomas. Cancer J 2014;20:66-72. Crossref

30. Ellison D, Kleinschmidt-DeMasters B, Park S-H. Epitheloid glioblastoma. In: Louis DN, Ohgaki H, Wiestler OD, Cavenee WK, editor. WHO Classification of Tumors of the Central Nervous System, Revised 4t. France: International Agency for Research on Cancer (IARC); 2016. p. 50,51.

31. Karremann M, Gielen GH, Hoffmann M, Wiese M, Colditz N, Warmuth-Metz M, et al. Diffuse high-grade gliomas with H3 K27M mutations carry a dismal prognosis independent of tumor location. Neuro Oncol 2018;20:123-31. Crossref

32. Louis DN, Giannini C, Capper D et al. cIMPACT-NOW update 2: Diagnostic clarifications for diffuse midline glioma, H3 K27Mmutant and diffuse astrocytoma/anaplastic astrocytoma, IDHmutant Acta Neuropathol 2018;135:639-42. Crossref

33. Thotakura M, Tirumalasetti N, Krishna R. Role of Ki-67 labeling index as an adjunct to the histopathological diagnosis and grading of astrocytomas. J Cancer Res Ther 2014; 10(3): 641-5. Crossref 
34. Santosh V, Sravya P, Gupta T et al. ISNO consensus guidelines for practical adaptation of the WHO 2016 classification of adult diffuse gliomas. Neurol India 2019; 67(1):173-82. Crossref

35. Louis DN, Aldape K, Brat DJ et al. cIMPACT-NOW (the consortium to inform molecular and practical approaches to CNS tumor taxonomy): A new initiative in advancing nervous system tumor classification. Brain Pathol 2017;27:851-2. Crossref
36. Rajeswarie RT, Rao S, Nandeesh BN et al. A simple algorithmic approach using histology and immunohistochemistry for the current classification of adult diffuse glioma in a resourcelimited set-up. J Clin Pathol 2018;71:323-9. Crossref 